\title{
Knowledge, Attitude and Practices of First Aid among Non-medical Students of Karachi University
}

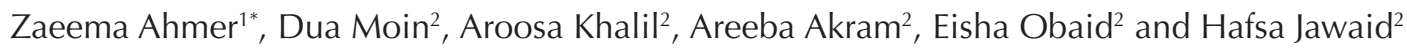 \\ ${ }^{1}$ APPNA Institute of Public Health, JSMU, Karachi, Pakistan \\ JSMU, Karachi, Pakistan
}

\begin{abstract}
Objective: To assess knowledge, attitude and practices regarding commonly encountered first aid scenarios among non-medical undergraduate students of Karachi University (KU).

Methods: A cross-sectional study was conducted in KU. Institutional Review Board approval was taken from Jinnah Sindh Medical University. At KU, permission was taken from concerned authorities for data collection, sample comprised of 386 students. Students were selected on convenience and availability from various departments of Arts, Business, Social Sciences, Islamic Studies and Pharmacy. Written consent was obtained from the students. Data was analyzed on SPSS 20.
\end{abstract}

Results: Out of 386 participants, the majority of students $(67.1 \%)$ were willing to attend sessions on first aid. Those who had correct knowledge were more willing to attend the sessions $(p<0.001)$, but were found to be reluctant in providing first aid to victims $(p<0.042)$. Significant difference in frequency of self-assume knowledge among actual knowledge groups was only found for management of boiling water $(p=0.021)$. Majority of the participants with self-assumption of correct knowledge $(n=210,65.2 \%)$ had no accurate knowledge for providing first aid management of burns with boiling water.

Conclusion: Knowledge regarding commonly encountered first aid incidents among KU students was found to be low. However, they showed interest in acquiring this knowledge. It is suggested that first aid training programs should be made part of academic curriculum of schools, colleges and universities and overall awareness regarding its acquisition should be spread among communities.

Keywords: First aid, choking, hypoglycemia, burns, heat stroke.

\section{INTRODUCTION}

Accident and injuries are commonly observed incidents that cannot be omitted from someone's life. These injuries are usually handled by inexperienced bystander at the accident site. These injuries can result in serious medical complications if first aid is not administered properly and timely. Whenever a casualty of any nature occurs, victim needs immediate assistance until proper medical help arrives at the scene. Therefore, implementation of first aid is meaningful to victim in emergency [1].

First aid is defined by the National First Aid Advisory Board as "management and manifestations performed by a layman person or by a victim with minimal or no medical equipment [2].

In a study done at Kuwait University, only $16.5 \%$ out of 562 students between age groups 18 to 23 year reported knowledge regarding unconscious pulse. Whereas knowledge regarding choking, collapse with chest pain, convulsions, triage in bleeding and fracture was reported as $53.9 \%, 83.3 \%, 24.2 \%$ and $66.7 \%$ respectively [3].

Astudy done in Greece on industrial workers, with sample size of 236 out of which 40 workers (Group A) were trained and 196 (Group B) were untrained with mean

\footnotetext{
* Corresponding Author: Zaeema Ahmer, APPNA Institute of Public Health Jinnah Sindh Medical University, Karachi, Pakistan;

Email: zaeema.ahmer@jsmu.edu.pk

Received: April 08, 2020; Revised: April 29, 2020; Accepted: May 18, 2020

DOI: https://doi.org/10.37184/lnjpc.2707-3521.1.23
}

value of 62.7 and 50.4 respectively. Group A was trained on first aid by a team of doctors. Answers of normal values of pulse, blood pressure, breaths, definition of cardio pulmonary resuscitation (CPR), number of chest compression, mouth-to-mouth ventilation, vital signs and CPR practice were at $67.5 \%, 35 \%, 47.5 \%, 95 \%, 25 \%$, $32.5 \%$, and $5 \%$ of group $\mathrm{A}$ and at $32.8 \%, 18.4 \%, 30.6 \%$, $72.4 \%, 26 \%, 36.7 \%$, and $1 \%$ respectively [4].

In an epidemiological prospective study in Vienna to determine the provided first aid measures in pre-hospital trauma settings and the quality of first aid, a total of 2812 cases were documented in which bystander were present in $57 \%$ of the cases. The commonly required first aid measures were application of a dressing and positioning of the patient. Mostly bystander had no training in first aid or only attended first aid course to have a driving license [5].

First aid is considered as a basic practice that should be universal irrespective of profession and age as it may prove to be lifesaving [6]. One study done in Turkey indicated that chances of death increased from $35 \%$ in first five minutes to $54 \%$ in 30 minutes of injury [7]. The bystander or nearby person if having adequate knowledge of first aid can prove to be a tool that alters the possibility from death to life, from permanent to temporary or no disability and from long hospitalization to a rapid recovery [8]. A study was conducted in Australia on 112 people who died during pre-hospital traumatic 
cardiac arrest. Out of them, $4.5 \%$ died due to lack of first aid and delayed ambulance service at that time [9].

Burns are commonly observed traumatic injury. But its significant knowledge and timely management can remarkably bring good outcomes for patients [10]. A KAP study was done in Aga Khan University which showed that non-medical students had insufficient knowledge about first aid. A total of 446 students were asked to fill a questionnaire. The mean number of correct answers of students who took first aid training was 10.3 and the mean number of correct answers by students without first aid knowledge was 7.84. Similarly, the mean number of correct answers of medical students with first aid training was 11.2 whereas mean of non-medical student's answer was 7.2 [11].

The level of knowledge of first aid and basic life support in trained and untrained medical students was done in three private medical colleges of Karachi. Comparison between trained and untrained students was found to be non-significant. Only the mean number of correct answers for trained students was $6.13 \pm 2.1$ while $4.94 \pm 2.06$ out of the total 13 questions for untrained students. The results of trained students were better than the untrained but the mean of trained was less than $50 \%$ which was not significant [12].

First aid providers possess critical position in natural disasters such as earthquake, flood and emergency situations like heat stroke. An investigation was done among undergraduate medical students to study the awareness of basic life support (BLS) and cardio pulmonary resuscitation through questionnaire by the students of Jinnah Medical and Dental College and Dow International Medical College in 2009. The results indicated that half of the undergraduate medical students had a general idea of BLS but on the contrary, $18 \%$ of students gave incorrect answers to the questions on skills involved in BLS. There were $36.6 \%$ students who were unaware of both about the general concept of BLS and its skills [13].

In Pakistan, people face daily accidental injuries due to burns, traffic accidents and more recently heatstroke related emergencies which is an emerging serious condition in Karachi for the past two years. First aid appears to be beneficial in such conditions. But unfortunately, first aid courses are much less provided in developing countries [14]. The main purpose of our study is primarily to evaluate the general first aid knowledge, attitude and practices among the undergraduate nonmedical students of Karachi.

\section{METHODS}

A cross-sectional study was conducted between June 2018 to January 2019 with IRB approval being taken from Jinnah Sindh Medical University. At Karachi University permission was taken from concerned authorities for data collection. The sample size of 385 was calculated by $\mathrm{WHO}$ calculator with confidence level of $95 \%$, margin of error $5 \%$ and assuming $50 \%$ prevalence. $50 \%$ prevalence was used as no previous study was found which assessed the KAP of non-medical students of Karachi regarding first aid. Students were selected on convenience and availability from various departments of Arts, Social Sciences, Business, Islamic Studies and Pharmacy. Written consent was obtained from the students who volunteered for participation. Research topic was briefly explained to make it easy for students to comprehend the questions properly. The questionnaire was developed based on extensive literature search. Face validity of the questionnaire was done by subject experts. It consisted of three sections. First section enquired information on demographic variables like age, gender, faculties study participants were studying in etc. Section two consisted of questions related to knowledge, attitude and practices regarding first aid which evaluated their responses to acquiring first aid knowledge and if any sessions were arranged by their educational institutes. Self-assumption of correct knowledge was assessed by a question on whether study participant knew about first aid, by answering a 'yes' or 'no' item, while marking a wrong response on scenario-based BCQ questions in the next section. Attitude was assessed by an item with responses like 'I will attend the session', 'I will not attend the session', 'I might or might not attend the session' and 'I have attended already enough sessions and have enough knowledge on 'First Aid'. Practice was operationalized by a question on whether study participant had provided first aid ever to anyone or not by a 'yes' or 'no' scale. Last section comprised of seventeen questions, each with three incorrect and one correct response to knowledge regarding different first aid scenarios like heat exhaustion, heat stroke, different types of burns, hypoglycemia and bleeding cuts etc. Researchers had the key with them. Correct knowledge was gauged when study participant answered the correct response on the provided BCQtype questionnaire whereas incorrect knowledge was marked for a study participant who answered the wrong response to the provided BCQ-type questionnaire. Pretesting of the questionnaire was done and after that the questionnaires were distributed among students. It took approximately 30 minutes for students to fill each form. The data was then analyzed and subjected to statistical inference by Statistical Package for the Social Sciences (SPSS) software, version 20. Categorical variables were expressed as frequencies and percentages. The Chisquare test was applied to assess between categorical variables. P-value $<0.05$ was taken as statistically significant.

\section{RESULTS}

Table 1 displays the sociodemographic characteristics, attitudes and practices of the undergraduate non-medical students of Karachi University and its association with their self-assumed knowledge regarding first aid. 
Table I: Socio -demographic characteristics, attitude and practice regarding first aid and its association with self-assumption of correct knowledge in study participants $(n=386)$.

\begin{tabular}{|c|c|c|c|c|}
\hline- & Total n (\%) & $\begin{array}{c}\text { Self-assumption of Correct } \\
\text { Knowledge } \mathrm{n}(\%)\end{array}$ & $\begin{array}{c}\text { Self-assumption of } \\
\text { Incorrect Knowledge } \mathrm{n}(\%)\end{array}$ & $p$-value \\
\hline \multicolumn{5}{|l|}{ Socio-demographic Variables: } \\
\hline \multicolumn{5}{|l|}{ Age (in years) } \\
\hline $17-21$ & $208(54)$ & $181(87.1)$ & $27(12.9)$ & \multirow{2}{*}{0.426} \\
\hline $22-34$ & $178(46)$ & $141(79.2)$ & $37(20.7)$ & \\
\hline \multicolumn{5}{|l|}{ Gender } \\
\hline Male & $101(26.2)$ & $83(82.2)$ & $18(17.8)$ & \multirow{2}{*}{0.696} \\
\hline female & $285(73.8)$ & 239 (83.9) & $46(16.1)$ & \\
\hline \multicolumn{5}{|l|}{ Faculty } \\
\hline Arts & $201(52.1)$ & $168(83.6)$ & $33(16.4)$ & \multirow{5}{*}{0.695} \\
\hline Business & $23(6.0)$ & $17(73.9)$ & $6(26.1)$ & \\
\hline Social Sciences & $138(35.8)$ & $116(84.1)$ & $22(15.9)$ & \\
\hline Pharmacy & $3(0.8)$ & $3(100)$ & $0(0)$ & \\
\hline Islamic Studies & $21(5.4)$ & $18(85.7)$ & $3(14.3)$ & \\
\hline \multicolumn{5}{|c|}{ Attitude: } \\
\hline \multicolumn{5}{|c|}{ Willingness to attend first aid session if given opportunity } \\
\hline I will attend the session & $259(67.1)$ & $225(86.9)$ & $34(13.1)$ & \multirow{4}{*}{$<0.001$} \\
\hline I will not attend the session & $27(7.0)$ & $14(51.9)$ & $13(48.1)$ & \\
\hline I might or might not attend the session & $81(21.0)$ & $65(80.2)$ & $16(19.8)$ & \\
\hline $\begin{array}{l}\text { I have already attended session and I have } \\
\text { enough skills regarding first aid }\end{array}$ & $19(4.9)$ & $18(94.7)$ & $1(5.3)$ & \\
\hline \multicolumn{5}{|c|}{ Practice: } \\
\hline \multicolumn{5}{|c|}{ Have you provided any sort of first aid to someone? } \\
\hline Yes & $122(31.6)$ & $108(88.5)$ & $14(11.5)$ & \multirow{2}{*}{0.042} \\
\hline No & $264(68.4)$ & $214(81.1)$ & $50(18.9)$ & \\
\hline
\end{tabular}

Table 2: Relationship between correct knowledge and self-assumption of correct knowledge of non-medical students of University of Karachi $(n=386)$.

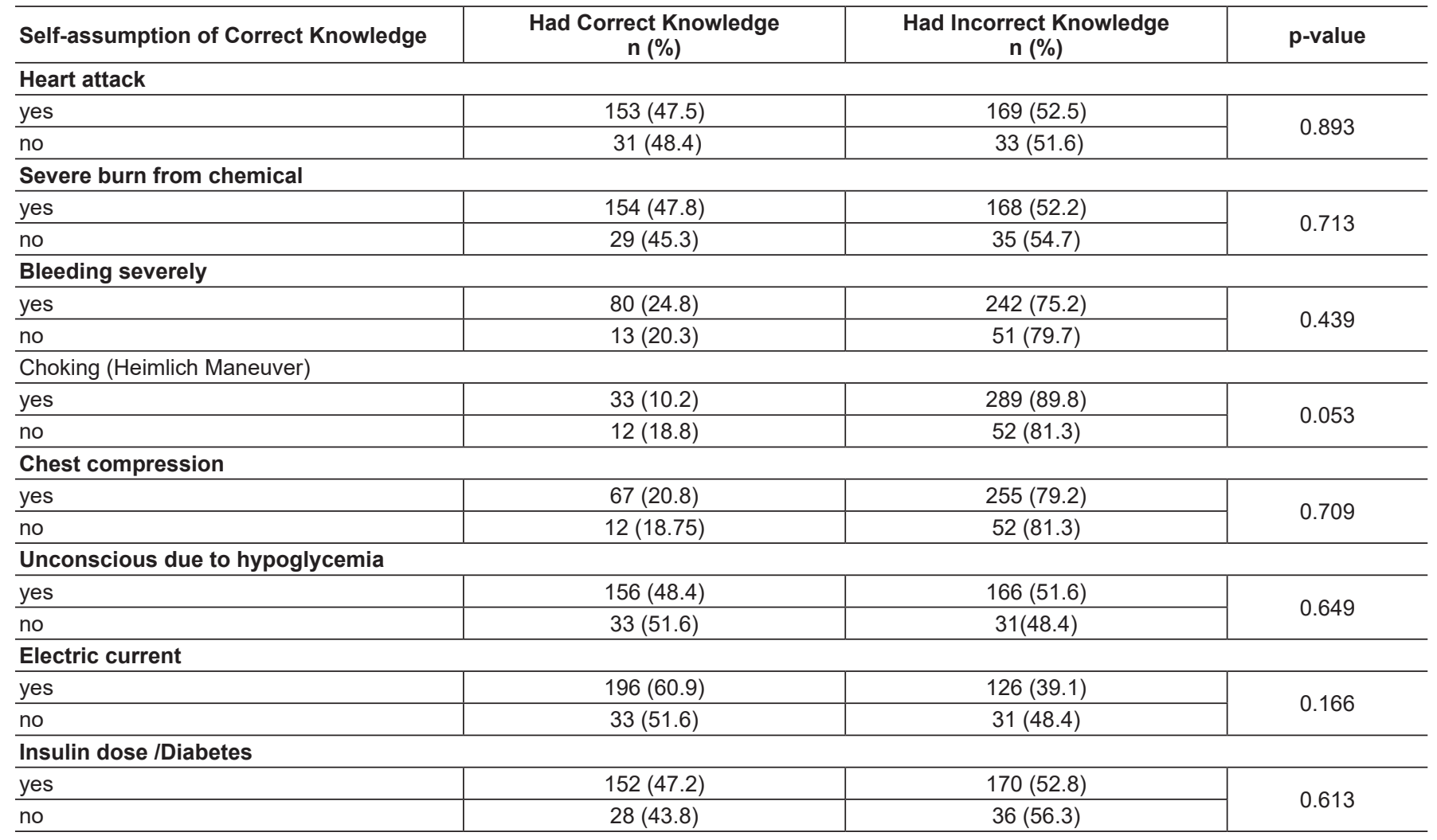




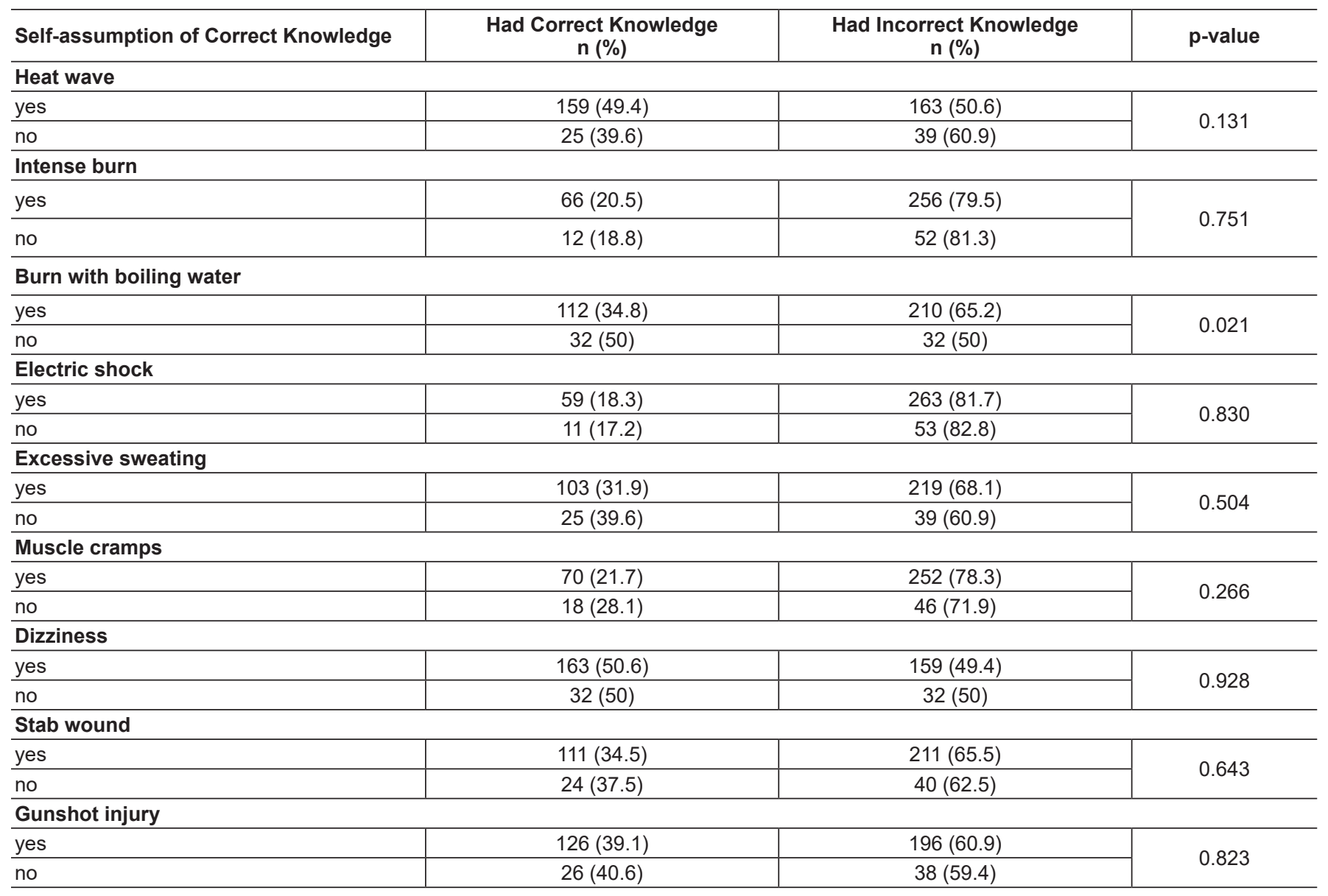

Table 3: Distribution of study participants according to practices and knowledge of First Aid( $n=386)$.

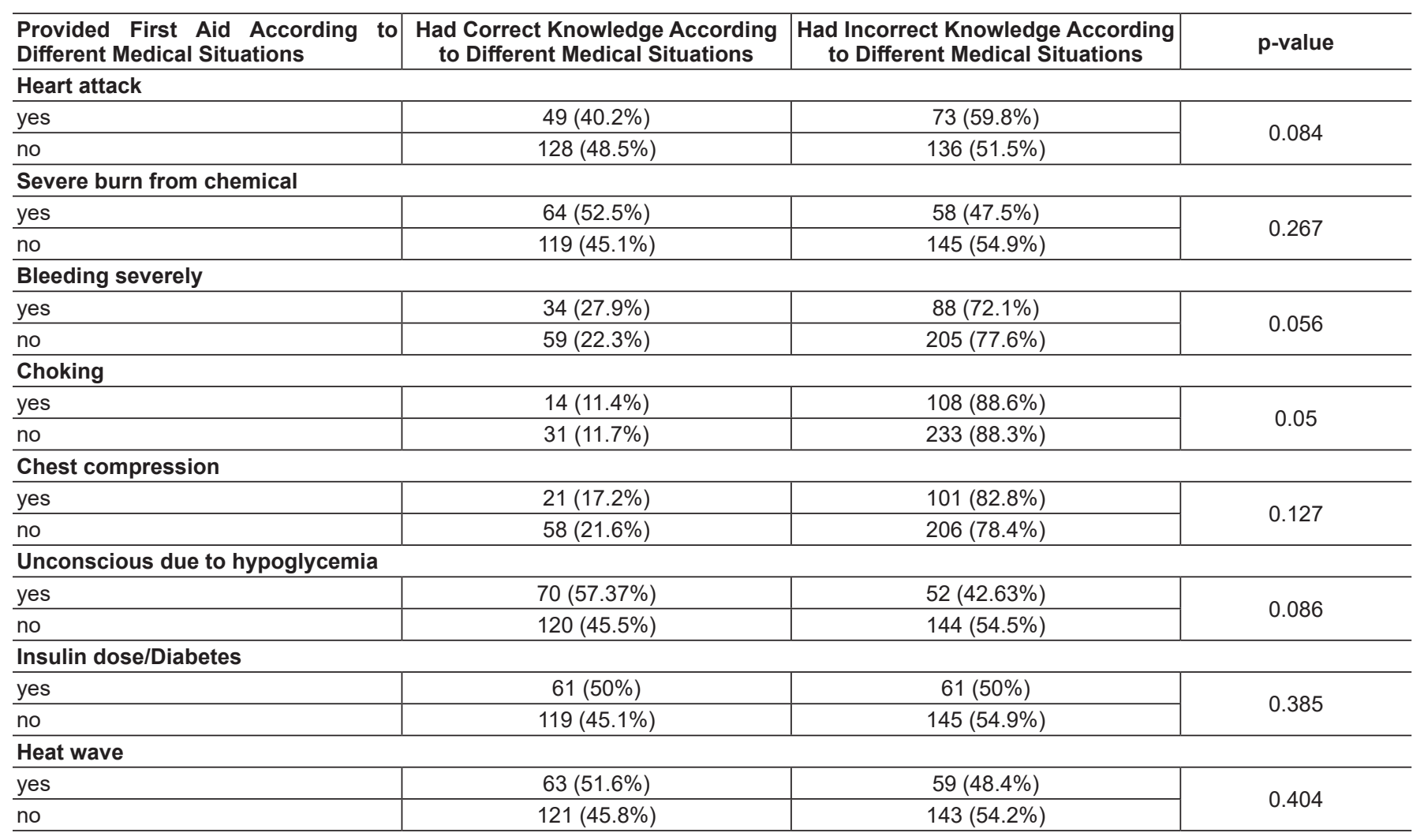




\begin{tabular}{|c|c|c|c|}
\hline \multicolumn{4}{|c|}{ Intense burn } \\
\hline yes & $26(21.3 \%)$ & $96(78.7 \%)$ & \multirow{2}{*}{0.218} \\
\hline no & $52(19.7 \%)$ & $212(80.3 \%)$ & \\
\hline \multicolumn{4}{|c|}{ Burn with boiling water } \\
\hline yes & $44(36.1 \%)$ & $76(63.9 \%)$ & \multirow{2}{*}{0.731} \\
\hline no & $100(37.9 \%)$ & $164(62.1 \%)$ & \\
\hline \multicolumn{4}{|c|}{ Electric shock } \\
\hline yes & $21(17.2 \%)$ & $101(82.8 \%)$ & \multirow{2}{*}{0.911} \\
\hline no & $49(17.4 \%)$ & $215(88.6 \%)$ & \\
\hline \multicolumn{4}{|c|}{ Excessive sweating } \\
\hline yes & $37(30.3 \%)$ & $85(69.7 \%)$ & \multirow{2}{*}{0.661} \\
\hline no & $92(34.8 \%)$ & $172(65.2 \%)$ & \\
\hline \multicolumn{4}{|c|}{ Muscle cramps } \\
\hline yes & $23(18.9 \%)$ & $99(81.2 \%)$ & \multirow{2}{*}{0.546} \\
\hline no & $65(24.6 \%)$ & $199(75.4 \%)$ & \\
\hline \multicolumn{4}{|c|}{ Dizziness } \\
\hline yes & $63(51.6 \%)$ & $59(48.4 \%)$ & \multirow{2}{*}{0.565} \\
\hline no & $132(50 \%)$ & $132(50 \%)$ & \\
\hline \multicolumn{4}{|c|}{ Stab wound } \\
\hline yes & $48(39.3 \%)$ & $74(60.7 \%)$ & \multirow{2}{*}{0.244} \\
\hline no & $87(32.9 \%)$ & $177(67.1 \%)$ & \\
\hline \multicolumn{4}{|c|}{ Gunshot injury } \\
\hline yes & $60(49.2 \%)$ & $62(50.8 \%)$ & \multirow{2}{*}{0.018} \\
\hline no & $92(34.8 \%)$ & $172(65.2 \%)$ & \\
\hline
\end{tabular}

Total 386 participants were enrolled into the study. The mean age of the students was $21.33+2.46$ years. Out of them, 208(54\%) belonged to the age group 17-21 years, whereas $46 \%(n=178)$ belonged to the age group 2234 years. Among the study participants, $26.2 \%(n=101)$ were males whereas $73.8 \%(n=285)$ were females.

The majority of the participants belonged to the Faculty of Arts ( $n=201,52.1 \%)$, whereas $138(35.8 \%)$ belonged to the Faculty of Social Sciences. Remaining belonged to the Faculty of Business, Islamic Studies and Pharmacy as $23(6 \%), 21(5.4 \%)$ and $3(0.8 \%)$ respectively.

Regarding their attitude, majority, i.e. $67.1 \%(n=259)$ were willing to attend the session. Those who had knowledge regarding first aid were more willing to attend the session $(p<0.001)$. But, as far as practice was concerned, in spite of having first aid knowledge most of the students were reluctant to provide first aid to the victim $(p<0.042)$.

Table 2 shows relationship between correct and incorrect knowledge and self-assumption of correct knowledge of these students. Study participants with incorrect knowledge, $65.2 \%(n=210)$ regarding providing first aid in burns with boiling water thought that they had the correct knowledge as compared to $50 \%(n=32)$ participants $(p=$ 0.021 ). There was no significant relationship between self-assumed correct knowledge of other first aid conditions with having the correct knowledge.

Table 3 indicates distribution of study participants according to practices and knowledge of first aid. Participants who had incorrect knowledge $(n=172$,
$65.15 \%$,) regarding gunshot injury were also reluctant to provide first aid to such victims $(p=0.018)$. There was no significant relationship among knowledge regarding other first aid situations and providing first aid.

\section{DISCUSSION}

Our study found that correct knowledge among nonmedical students was very low. However, proportion of students who considered themselves as knowledgeable was high $83.4 \% \quad(n=322)$. Very few students had previously attended sessions on the basis of which they considered themselves capable enough to cope with any such situation $4.9 \%(n=19)$. This is in line with a study conducted in parents and caregivers about first aid where $64.5 \%$ thought they knew about first aid, however only $37.6 \%$ were ever trained in first aid [15]. The reason for this low score may be lack of knowledge about first aid, lacking a sense of confidence, or they had never encountered any such situation or it may also be because this basic skill is not emphasized upon in our institutions. Similar results were found in a study conducted at Agha Khan Hospital, Karachi in which most of the students did not know about places where these courses are offered [11]. It was found however that the majority of students, $67.1 \%(n=259)$ were interested in attending first aid training sessions. First aid training can bring good outcomes. A study conducted in Pakistan in 2011 among medical students found that knowledge of students who were trained in First Aid-BLS, was better than those who were untrained [12]. In our study, knowledge regarding following first aid situations was assessed: bleeding, gunshot injury, stab wound injury, choking, heart attack, CPR, burns, electrocution, hypoglycemia. 
Control of bleeding is one of important and basic first aid skill through which first aid provider can significantly influence outcome of injury. It is therefore important to know about measures to stop bleeding at site of injury before medical help is sought like applying direct pressure on wound or putting a gauze piece on bleeding site if it does not get controlled by applying pressure. In our study it was found that only few participants had selfassumed and also correct knowledge about it $24.1 \%$ $(n=80)$.

Results found for frequency of self-assumed and also correct knowledge regarding gunshot wounds was $39.1 \%(n=126)$ and for stab wound injury was $34.5 \%(n=111)$. Awareness regarding its prevention and maneuver to deal with it in case of incident can significantly decrease number of deaths. In our study few participants responded correctly about choking and Heimlich maneuver $10.2 \% \quad(n=33)$. Participants with correct and self-assumed correct knowledge for heart attack emergency pre hospital management were $47.5 \%$ $(n=153)$ and for a number of compressions, in one cycle of CPR were $27.8 \%$ ( $n=67)$. This result is comparable to a study conducted in Taiwan for assessing self-efficacy of first aid in home accidents in parents of children 0-4 years of age in which parents' knowledge about choking and CPR was found to be lowest [16].

Burns is a common emergency seen in hospital settings. Adequate knowledge and its timely implementation can decrease the extent and severity of injury as reflected in a study conducted in Baltimore Regional Burn Centre from July 1976 to June 1980 . This study showed that those burns patients who had received appropriate first aid at site of incident showed significantly less full-thickness of dermal injury as compared to those who didn't receive it [17]. But, it was found in our study that the majority of the participants, $52.6 \%(n=203)$ didn't know the correct management of burns from chemicals and $79.8 \%(n=308)$ didn't know the correct management of intense burns. Adequate knowledge regarding burns management and its practices can prevent serious complications. In our study, significant difference between self-assumed and actual knowledge for burns management with boiling water was found ( $p$ value $=0.021$ ). There were $65.2 \%$ $(n=210)$ students who didn't know the management of a person burnt with boiling water, yet were practically applying their own management, as compared to $34.8 \%$ $(n=112)$ students. This finding is comparable to a study conducted in Mangalore City, India, in 2011 among students of a medical college which showed that only $13.8 \%$ students knew correctly the management of burns [18]. Another study conducted in 2020 at Karachi among medical and non-medical students regarding the knowledge of first aid management of burns, it was found that majority of participants had insufficient knowledge regarding it. However, medical students had better knowledge score than non-medical students [19].
Another aspect which we assessed was knowledge and management regarding electric shock. Electric burns cause severe damage to tissues and cardiac arrest by interrupting conduction through the myocardium, If someone suffers from electric shock, proper knowledge and its implementation can save the life of the victim and can decrease the severity of injury. But it was found in our study that the majority of the participants of our study, $81.2 \%(n=316)$ didn't know how to manage a person with electric shock. Medical researches and experiences show that a significant number of mortalities can be prevented if proper CPR is applied at accident place [19].

Drastic climate changes and accompanied heat waves are now considered an emerging global concern as reflected by the high mortality and morbidity rates associated with it $[19,20]$. There were $52.3 \% \quad(n=202)$ students, who had incorrect knowledge regarding managing patients of heat waves, which is similar to other studies [21, 22]. This maybe because study participants are not properly guided through organized and repeated sessions aimed at developing skills and necessitating people with awareness programs stressing on what to do if one's body gets overheated and dehydrated. Also, because our target population was of a significantly lower age group, and not as such vulnerable to heat related illnesses compared to extremes of age population hence not as concerned as shown by other studies [23].

When assessing knowledge of hypoglycemic conditions, $53.3 \%(n=206)$ students were unaware of what to do if a diabetic person is hypoglycemic the results were similar to other studies [11, 22]. This can be due to be unable to identify the sign and symptoms of this condition, since these can overlap with other normal physiological phenomenon especially in old age population. Similarly, in conditions of fainting due to hypoglycemia, there were $51.1 \%(n=197)$ students who did not know how to help because they were either oblivious to the ways to help or not confident enough to act upon their instincts due to their decreased understanding of the matter as they are not provided with sessions that can increase and help retain their knowledge and confidence regarding such problems [12].

\section{STRENGTHS AND LIMITATIONS OF THE STUDY}

This study was conducted in Karachi University because of numerous students and diversity among them. However, since it was a cross-sectional study, results cannot be generalized to entire non-medical undergraduates of the city. Also, the possibility of response bias cannot be ruled out.

\section{CONCLUSION}

Overall, correct knowledge regarding first aid among Karachi University students was found to be low. They did however show interest in acquiring first aid knowledge. It 
is recommended that first aid training programs regarding frequently occurring medical conditions should be made part of academic curriculum of schools, colleges and universities.

\section{CONFLICT OF INTEREST}

Authors declare no conflict of interest.

\section{ACKNOWLEDGEMENTS}

Declared none.

\section{REFERENCES}

1. Khatatbeh M. First aid knowledge among university students in Jordan. Int J Prev Med 2016; 7: 24

2. Yurumez Y, Yavuz Y, Saglam H, Köken R, Tunay K. Evaluation of the level of knowledge of first aid and basic life support of the educators working in preschools. Acad Emerg Med 2007; 5(3): 17 20.

3. Al-Khamees N. A field study of first aid knowledge and attitudes of college students in Kuwait University. Coll Stud J 2006; 40(4): 91626 .

4. Hatzakis KD, Kritsotakis El, Angelaki HP, Tzanoudaki IK, Androulaki ZD. First aid knowledge among industry workers in Greece. Ind Health 2005; 43(2): 327-32.

5. Mauritz W, Pelinka LE, Kaff A, Segall B, Fridrich P. First aid measures by bystanders at the place of accident. A prospective, epidemiologic study in the Vienna area. Wien Klin Wochenschr 2003; 115(19-20): 698-704.

6. Metin I, Mutlu C. Level of knowledge about first aid of the university students. Trakia J Sci 2010; 8(2): 262-5.

7. Bildik F, Kılıçaslan I, Doğru C, Keleş A, Demircan A. The need for first aid awareness among candidate teachers. Turk J Emerg Med 2011; 11(4): 166-70.

8. Tomruk O, Soysal S, Gunay T, Cimrin AH. First aid: level of knowledge of relatives and bystanders in emergency situations. Adv Ther 2007; 24(4): 691.

9. Ashour A, Cameron P, Bernard S, Fitzgerald M, Smith K, Walker T. Could bystander first aid prevent trauma deaths at the scene of injury? Emerg Med Australas 2007; 19(2): 163-8.

10. Riaz R, Riaz L, Khan J, Baloch M. Survey on knowledge of first aid management of burns amongst medical and non-medical students in Karachi, Pakistan: need for an educational intervention. Cureus 2020; 12(1): e6674.
11. Khan A, Shaikh S, Shuaib F, Sattar A, Samani SA, Shabbir Q, et al. Knowledge attitude and practices of undergraduate students regarding first aid measures. JPMA 2010; 60(1): 68.

12. Abbas A, Bukhari SI, Ahmad F. Knowledge of first aid and basic life support amongst medical students: a comparison between trained and un-trained students. JPMA 2011; 61(6): 613-6.

13. Zaheer H, Haque Z. Students' corner-awareness about BLS (CPR) among medical students: status and requirements. JPMA 2009; 59(1): 57.

14. Santos SV, Margarido MRRA, Caires IS, Santos RAN, Souza. SG, Souza JMA, et al. Basic life support knowledge of first year university students from Brazil. Braz J Med Biol Res 2015; 48(12): 1151-5.

15. Wanot J, Lubon D, Kurczabinska D, Nowicka M, Goj K. Parents' and caregivers' theoretical and practical knowledge of first aid in case of accidents and minor injuries in children. Wiad Lek 2004; 57 Suppl 1: 323-6.

16. Wei YL, Chen LL, Li TC, Ma WF, Peng NH, Huang LC. Self-efficacy of first aid for home accidents among parents with 0- to 4-yearold children at a metropolitan community health center in Taiwan. Accid Anal Prev 2013; 52: 182-7.

17. Leonard LG, Scheulen JJ, Munster AM. Chemical burns: effect of prompt first aid. J Trauma 1982; 22(5): 420-3.

18. Joseph N, Kumar G, Babu Y, Nelliyanil M, Bhaskaran U. Knowledge of first aid skills among students of a medical college in mangalore city of South India. Ann Med Health Sci Res 2014; 4(2): 162-6.

19. Goduhan AK, Kshirsagar AY, Zagade TB. A study to determine the effectiveness of basic life support training on knowledge of life saving skills among college students in selected colleges at Jaipur for degree students. IJSR 2017; 6(6): 2712-22.

20. Fouillet A, Rey G, Laurent F, Pavillon G, Bellec S, GuihenneucJouyaux C, et al. Excess mortality related to the August 2003 heat wave in France. Int Arch Occup Environ Health 2006; 80(1): 16-24.

21. Haider K, Anis K. Heat wave death toll rises to 2,000 in Pakistan's financial hub. Available from: https://www.bloomberg.com/news/ articles/2015-06-24/heat-wave-death-toll-rises-to-2-000-inpakistan-s-financial-hub.

22. Mathew S, Salman P, Khurshid S, Luke AM. Awareness of first aid among undergraduate students in Ajman, UAE. IOSR J Dental Med Sci 2016; 15(6): 30-8.

23. Rauf S, Bakhsh K, Abbas A, Hassan S, Ali A, Kächele H. How hard they hit? Perception, adaptation and public health implications of heat waves in urban and peri-urban Pakistan. Environ Sci Pollut Res 2017; 24(11): 10630-9. 